\title{
Uterotrophic effects of cow milk in immature ovariectomized Sprague-Dawley rats
}

\author{
Hong Zhou $\cdot$ Li-Qiang Qin $\cdot$ De-Fu Ma \\ Yan Wang $\cdot$ Pei-Yu Wang
}

Received: 21 June 2009/Accepted: 5 November 2009/Published online: 3 December 2009

(C) The Japanese Society for Hygiene 2009

\begin{abstract}
Objectives Milk contains considerable quantities of estrogens and progesterone and as such may be one of the risk factors for hormone-related cancers. To determine the hormonal effects of commercial and traditional types of milk, we performed uterotrophic tests.

Methods Forty-five rats were ovariectomized and divided into three groups of 15 animals each. The animals were kept for 7 days on powdered chow and one of three different liquids: commercial milk (C), traditional milk (T), or water. At autopsy, wet and dry uterine weights were determined. The cell heights of the uterine epithelium and endometrium were determined. The uterine 5-bromo-2deoxyuridine (BrdU) labeling index of the epithelium and endometrium gland epithelium was also assessed.

Results The weights of wet and dry uterus were $142 \pm 13$ and $112 \pm 10 \mathrm{mg}$ in the $\mathrm{C}$ group, $114 \pm 30$ and $91 \pm 24 \mathrm{mg}$ in the T group, and $87 \pm 6$ and $69 \pm 5 \mathrm{mg}$ in
\end{abstract}

H. Zhou and L.-Q. Qin contributed equally to this work.

H. Zhou · Y. Wang $(\bowtie)$

Department of Child, Adolescent and Women's Health, School of Public Health, Peking University,

Xueyuan Road 38, Haidian District, 100083 Beijing, China

e-mail: wangyanmail@hotmail.com

H. Zhou · D.-F. Ma · P.-Y. Wang ( $\bowtie)$

Department of Social Medicine and Health Education, School of Public Health, Peking University, Key Laboratory of Epidemiology, Ministry of Education, Xueyuan Road 38, Haidian District, 100083 Beijing, China

e-mail: wpeiyu@bjmu.edu.cn; wpeiyu@hsc.pku.edu.cn

L.-Q. Qin

Department of Nutrition and Food Hygiene, School of Radiation

Medicine and Public Health, Soochow University,

215123 Suzhou, China the $\mathrm{W}$ group. Significant differences in wet and dry uterus weights were found between all pairs of groups. The ratio of the wet uterine weight to body weight was significantly higher in the $\mathrm{C}$ and $\mathrm{T}$ groups than in the $\mathrm{W}$ group. The heights of the uterine epithelium and endometrium were higher and BrdU labeling index was greater in the $\mathrm{C}$ group than in the $\mathrm{T}$ and $\mathrm{W}$ groups.

Conclusions Commercially available milk and traditional milk have uterotrophic effects on young ovariectomized rats. Our findings indicate that these uterotrophic effects in the milk groups were partly due to the estrogen and progesterone in the milk.

Keywords Cow milk - Estrogen - Ovariectomized rat $\cdot$ Progesterone $\cdot$ Uterotrophic assay

\section{Introduction}

Endocrine disrupting compounds (EDCs) are chemicals that elicit adverse effects on humans and wildlife at very low concentrations, and their presence in the environment has raised worldwide concern $[1,2]$. Various EDCs are known to cause reproductive and developmental abnormalities and certain hormone-related cancers, such as prostate and breast cancers [3-5]. The potential consequences of human exposure to such endocrine disrupters has been the focus of much discussion [6]. Multiple in vivo and in vitro assays have been developed to test estrogenicity [7, 8]. In 1998, the U.S. Environmental Protection Agency recommended the in vivo uterotrophic response assay as the "gold standard" since it incorporates the effects of both metabolism and pharmacokinetics [9].

Milk is an important dietary staple in Western countries, and it is becoming increasingly popular in China where it 
has traditionally not been part of the diet. Most studies on milk have identified beneficial effects, such as the prevention of osteoporosis and the promotion of growth and development. However, milk also contains organochlorine pesticides and endogenetic estrogens, which are classified as EDCs [10]. Forty years ago, Armstrong and Doll reported an association between the intake of milk-based products and increased breast cancer mortality [11]. More recently, Ganmaa et al. reported close correlations between cheese and testicular cancer and between milk and prostate cancer [12]. However, epidemiological studies have yielded inconsistent results, ranging from a significantly increased risk to a significantly reduced risk [13-15]. Animal studies may provide some clues as to the effect of milk consumption on cancer risk. In an earlier study, we fed commercial milk to rats and found that it promoted the development of 7,12-dimethylbenz(a)anthracene (DMBA)-induced mammary tumors [16]. Based on the levels of hormones found in milk and rats' plasma, we considered estrogen to be the cause of the observed increase in the frequency of mammary tumors. However, endogenous estrogen, mainly derived from ovaries, was not taken into account.

Commercially available milk is the product of genetically improved dairy cows, who continue to lactate for almost the entire period of the pregnancy. In contrast, Mongolian traditional cows do not lactate during the latter half of pregnancy [17]. It is plausible that this traditional milk contains relatively low levels of estrogen and progesterone. As such, if is the ideal control for studies of commercial milk aimed at determining the effects of hormones. To the best of our knowledge, there have been published reports comparing commercially available milk with milk from such traditional sources.

We report here our evaluation of the estrogenic potential of milk and our comparison of the uterotrophic effects of commercial and traditional milk. We selected the immature rat as an experimental model because developing organisms are particularly sensitive to hormone-like chemicals [18].

\section{Materials and methods}

Animals and treatment

A total of 45 female Sprague-Dawley 5-week-old rats were obtained from Beijing Vital River Laboratory Animal Company (Beijing, China). The animals were housed individually in stainless-steel wire-bottomed cages in an air-conditioned room where the temperature was maintained $22 \pm 2^{\circ} \mathrm{C}$ and $50 \pm 10 \%$ relative humidity under a 12/12-h (light/dark) photoregimen. The experimental procedures and care of the animals followed the guidelines for animal experiments of the Peking University Health Science Center.

After 1 week acclimation, all rats were ovariectomized under anesthesia by ether inhalation. Two weeks later, the rats were randomly assigned to three groups of 15 rats each. Each groups received one of three different liquids: commercial milk (C), traditional milk (T) and tap water (W). Commercial milk, produced by dairy cows grazing on Inner Mongolian grassland, was purchased from a local supermarket. Traditional milk was collected from traditional cows grazing on the same grassland area in Inner Mongolia, China, but it was obtained through milking by nomads in the morning, then immediately placed in an ice box. The traditional milk was transported by airplane at $4^{\circ} \mathrm{C}$ to our laboratory on the same day and stored at $-18^{\circ} \mathrm{C}$. All rats consumed commercial rat chow and drank the respective liquids. The amount of liquid intake was recorded daily by calculating the liquid weight difference at 4:00 p.m. and 10:00 a.m. the next day. The intakes of chow and body weight were recorded each day.

Autopsy and morphologic studies

Seven days after exposure to the liquids, all rats were intraperitoneally injected with a single dose of $50 \mathrm{mg} / \mathrm{kg}$ body weight of 5-bromo-2'-deoxyuridine (BrdU, $12.5 \mathrm{mg} / \mathrm{ml}$ saline; Sigma Chemical, St. Louis, MO). Six hours later, all rats were sacrificed by ether inhalation. The uterus was quickly dissected after the removal of connective tissue, and wet uterine weight was recorded. The uterus was then gently punctured and dried by blotting to remove any remaining fluid, and the dried weight was recorded. The uterus was then fixed in formalin buffer and embedded in paraffin. Each paraffin-embedded uterus was cut into 3 - $\mu$ m-thick sections that were used for hematoxylin-eosin (H\&E) staining and immunohistochemical analysis.

For the immunohistochemical analysis, the de-paraffinized and rehydrated sections were subjected to microwaves for antigen retrieval. After cooling to room temperature, the sections were treated with $0.1 \mathrm{M} \mathrm{HCl}$ for 30 min. All sections were incubated with $1 \%$ hydrogen peroxide in phosphate-buffered saline for $1 \mathrm{~h}$ for blocking the endogenous peroxidase and then incubated with blocking solution for $1 \mathrm{~h}$. The sections were incubated with mouse anti-BrdU monoclonal antibody (Clone Bu33; Sigma Chemical) at a dilution of $1: 20$ at $4{ }^{\circ} \mathrm{C}$ overnight, with anti-mouse immunoglobulin $\mathrm{G}$ conjugates (DAKO, Glostrup, Denmark) at room temperature for $1 \mathrm{~h}$, and with horseradish peroxidase-conjugated avidin-biotin complex for $1 \mathrm{~h}$. All sections were routinely visualized by the peroxidase enzyme reaction with metal-enhanced 3,3'-diaminobenzidine (Pierce Co., Rockford, IL) in buffer solution containing $0.02 \%$ hydrogen peroxide for $5 \mathrm{~min}$. Finally, all 
sections were counterstained with hematoxylin to visualize immunostaining.

Heights of the epithelium and endometrium

HE-stained sections were evaluated for the height of the epithelium and endometrium using an Olympus BH-2 microscope (Olympus Corp., Tokyo, Japan) connected with an image analysis system (Video Micro-Meter, VM30; Olympus, Tokyo, Japan) as previously described [19]. The height was determined from the mean value of three measurements from each region.

Uterine labeling index of epithelium and endometrium gland epithelium

The uterine labeling index was assessed using the formula: uterine labeling index $=$ the number of BrdU-labeled nuclei/total number of cells $\times 100 \%$ [20]. A total of 1000 BrdU-labeled endometrial cells in the S-phase per animal were used to calculate the BrdU uterine labeling index. The number of labeled nuclei and the total number of cells were counted by at least two individuals who were unaware of the animal's group.

Measurement of estrogens and progesterone in milk

Five 1-ml samples of commercial milk were collected and mixed to produce a single sample for the hormone measurement. When traditional milk was collected, five 1-ml samples were obtained from different buckets and mixed to produce one sample for measurement. Five such samples of commercial and traditional milk were obtained. Commercial enzyme immunoassay (EIA) kits from American Laboratory Products Company (Windham, NH) were used to measure estrone and estradiol in milk. An EIA kit to measure the progesterone in cow milk was obtained from Cambridge Veterinary Science (Cambridge, UK). All experimental procedures followed the guidelines provided by the respective companies.
Measurements of hormone concentration in plasma

Before sacrifice, blood samples were obtained from tail veins using heparinized capillary tubes and centrifuged at $4^{\circ} \mathrm{C}$. Plasma estrone and $17 \beta$-estradiol concentrations were measured using the commercial EIA kit from American Laboratory Products Company. The plasma progesterone concentration was measured using a commercial enzymelinked immunosorbent assay (ELISA) kit from ImmunoBiological Laboratories (Hamburg, Germany).

Statistical analysis

Data were expressed as mean \pm standard deviation (SD) and analyzed using an analysis of variance (ANOVA) followed by Student's $t$ test using SPSS ver. 11.5 software for Windows (SPSS, Chicago, IL). $P$ values $<0.05$ were considered to be significant.

\section{Results}

The rats in the $\mathrm{W}$ group consumed more solid chow than those in the $\mathrm{C}$ and $\mathrm{T}$ groups $(p<0.001)$, but those in the $\mathrm{W}$ group drank less than those in the two milk groups $(p<0.001 ;$ Table 1). The average energy intakes were $72.5 \pm 7.1,73.6 \pm 6.1$, and $73.3 \pm 5.6 \mathrm{kcal} /$ day in the $\mathrm{W}$, $\mathrm{C}$, and $\mathrm{T}$ groups, respectively, and were not significantly different. As shown in Table 1, although there were no significant differences in body weight among the three groups, the weight of the peritoneum adipose was significantly lower in the $\mathrm{W}$ group than in the $\mathrm{C}$ and $\mathrm{T}$ groups $(p<0.01)$. Significant differences in wet and dry uterus weights were found between all pairs of groups in the order of $\mathrm{C}$ group $>\mathrm{T}$ group $>\mathrm{W}$ group. The ratio of the wet uterine weight to body weight was significantly higher in the $\mathrm{C}$ and $\mathrm{T}$ groups than in the $\mathrm{W}$ group.

The concentrations of estrone and estradiol were $150.2 \pm 8.4$ and $34.1 \pm 2.0 \mathrm{pg} / \mathrm{ml}$ in commercial milk, which was approximately 1.5-fold higher than the

Table 1 Effects of different types of milk and water on body and organ weights

\begin{tabular}{|c|c|c|c|c|c|c|c|}
\hline Test groups & $\begin{array}{l}\text { Liquid } \\
\text { consumption } \\
\text { (g/day/rat) }\end{array}$ & $\begin{array}{l}\text { Chow } \\
\text { consumption } \\
\text { (g/day/rat) }\end{array}$ & $\begin{array}{l}\text { Body } \\
\text { weight (g) }\end{array}$ & $\begin{array}{l}\text { Peritoneum } \\
\text { adipose } \\
\text { weight (g) }\end{array}$ & $\begin{array}{l}\text { Wet uterine } \\
\text { weight }(\mathrm{mg})\end{array}$ & $\begin{array}{l}\text { Dry uterine } \\
\text { weight }(\mathrm{mg})\end{array}$ & $\begin{array}{l}\text { Wet uterine } \\
\text { weight/body } \\
\text { weight }\left(10^{-4}\right)\end{array}$ \\
\hline Commercial milk & $43.6 \pm 2.0$ & $14.9 \pm 3.9$ & $312.2 \pm 15.1$ & $8.6 \pm 0.6$ & $142 \pm 13$ & $112 \pm 10$ & $4.5 \pm 0.4$ \\
\hline Traditional milk & $41.4 \pm 4.8$ & $15.3 \pm 4.6$ & $318.8 \pm 22.6$ & $8.4 \pm 1.1$ & $114 \pm 30 \mathrm{a}$ & $91 \pm 24 \mathrm{a}$ & $3.7 \pm 1.2$ \\
\hline Water & $33.8 \pm 5.2 \mathrm{~b}, \mathrm{~d}$ & $24.1 \pm 6.7 \mathrm{~b}, \mathrm{~d}$ & $307.0 \pm 16.4$ & $6.4 \pm 1.6 \mathrm{~b}, \mathrm{~d}$ & $87 \pm 6 b, c$ & $69 \pm 5 b, c$ & $2.8 \pm 0.3 \mathrm{~b}, \mathrm{c}$ \\
\hline
\end{tabular}

Values are given as the mean \pm standard deviation (SD)

Values followed by different letters indicate signficant differences. $a$ Significant difference from the commercial milk group $(p<0.01)$; $b$ significant difference from the commercial milk group $(p<0.001) ; c$ significant difference from the traditional milk group $(p<0.01)$; $d$ significant difference from the traditional milk group $(p<0.001)$ 
Table 2 The concentration of estrogens and progesterone in different types of milk

\begin{tabular}{lccc}
\hline Test groups & Estrone $(\mathrm{pg} / \mathrm{ml})$ & Estradiol $(\mathrm{pg} / \mathrm{ml})$ & Progesterone $(\mathrm{ng} / \mathrm{ml})$ \\
\hline Traditional milk & $98.5 \pm 12.4$ & $24.6 \pm 3.0$ & $0.2 \pm 0.3$ \\
Commercial milk & $150.2 \pm 8.4 \mathrm{a}$ & $34.1 \pm 2.0 \mathrm{a}$ & $20.1 \pm 2.1 \mathrm{a}$ \\
\hline
\end{tabular}

Independent samples $t$ test for comparison between groups. Values are given as the mean $\pm \mathrm{SD}$

Values followed by the letter ' $a$ ' are significantly different from the traditional milk group $(p<0.001)$

Table 3 The concentration of estrogens and progesterone in plasma

\begin{tabular}{llcc}
\hline Test groups & Estrone $(\mathrm{pg} / \mathrm{ml})$ & Estradiol $(\mathrm{pg} / \mathrm{ml})$ & Progesterone $(\mathrm{ng} / \mathrm{ml})$ \\
\hline Traditional milk & $58.5 \pm 8.4$ & $12.6 \pm 2.0$ & $0.8 \pm 0.2$ \\
Commercial milk & $63.2 \pm 6.4$ & $16.1 \pm 2.2 \mathrm{a}$ & $8.4 \pm 3.1 \mathrm{a}$ \\
Water & $24.5 \pm 4.6 \mathrm{a}, \mathrm{b}$ & $6.7 \pm 2.9 \mathrm{a}, \mathrm{b}$ & $0.4 \pm 0.3 \mathrm{a}, \mathrm{b}$ \\
\hline
\end{tabular}

Analysis of variance (ANOVA) for comparison among groups. Values are given as the mean \pm SD

Values followed by different letters indicate signficant differences. $a$ Significant difference from the traditional milk group $(n=15 ; p<0.001)$; $b$ significant difference from the commercial milk group $(n=15 ; p<0.001)$

Table 4 The height of the uterine epithelium and endometrium

\begin{tabular}{lll}
\hline Groups & Epithelium $(\mu \mathrm{m})$ & Endometrium $(\mathrm{mm})$ \\
\hline Commercial milk & $17.5 \pm 1.2$ & $0.56 \pm 0.01$ \\
Traditional milk & $13.1 \pm 3.1 \mathrm{a}$ & $0.42 \pm 0.07 \mathrm{a}$ \\
Water & $11.0 \pm 1.1 \mathrm{a}, \mathrm{b}$ & $0.37 \pm 0.03 \mathrm{a}, \mathrm{b}$ \\
\hline
\end{tabular}

ANOVA analysis for comparison among groups. Values are given as the mean $\pm \mathrm{SD}$

Values followed by different letters indicate signficant differences. $a$ Significant difference from the commercial milk group $(n=15$; $p<0.05) ; b$ significant difference from the traditional milk group $(n=15 ; p<0.001)$

concentrations of these substances in traditional milk. The progesterone concentration was almost 100-fold higher in commercial milk than that in traditional milk (Table 2). The plasma estrone concentration was significantly lower in the $\mathrm{W}$ group than in the $\mathrm{T}$ and $\mathrm{C}$ groups (Table 3 ). Although there was no significant difference in plasma estrone concentration between the two milk groups, the plasma concentrations of estradiol and progesterone were significantly higher in the $\mathrm{C}$ group than in the $\mathrm{T}$ group.

The heights of the uterine epithelium and endometrium were in the order of $\mathrm{C}$ group $>\mathrm{T}$ group $>\mathrm{W}$ group, with significant differences between all pairs of groups. The greatest heights were found in the $\mathrm{C}$ group, $17.5 \pm 1.2 \mu \mathrm{m}$ and $0.56 \pm 0.01 \mathrm{~mm}$, respectively (Table 4).

Endometrium immunostaining to identify BrdU-labeled cells in the three groups is shown in Fig. 1. Labeled endothelia are distinguishable due to the appearance of a red-brown nucleus, with peri-nuclear immunostaining indicating the S-phase (BrdU is a synthetic nucleoside that is an analog of thymidine and can be incorporated into the newly synthesized DNA of replicating cells). The C group had the highest percentage of labeled cells in both the uterine epithelium $(8.9 \pm 1.1 \%)$ and endometrium gland epithelium $(7.9 \pm 0.9 \%)$, followed by the $\mathrm{T}$ group and then the $\mathrm{W}$ group (Table 5). There were significant differences between all the pairs of groups. These results indicate that exposure to commercial or traditional milk led to a significant increase in the number of S-phase cells in the uterine epithelium and endometrium gland epithelium and that the effect was greater in the $\mathrm{C}$ group than in the $\mathrm{T}$ group.

\section{Discussion}

The results of our study suggest that commercial milk has weak uterotrophic effects on the immature ovariectomized rat. As such, they are consistent with those of Ganmaa et al.'s study where a mixture denoted "artificial milk" was used to mimic commercial milk [21]. Although protein, fat, and carbohydrate were present in this artificial milk at typical levels, the concentrations of minerals and contaminants were significantly different from those of real milk $[10,22]$. The main improvement of the study reported here is the use of traditional milk.

Mongolian cows traditionally fed only on pasture grass and do not lactate during the latter half of pregnancy. In contrast, modern genetically improved dairy cows, such as the Holstein, are fed on a combination of grass and concentrates and allowed to lactate during the latter half of pregnancy when the estrogen and progesterone levels 

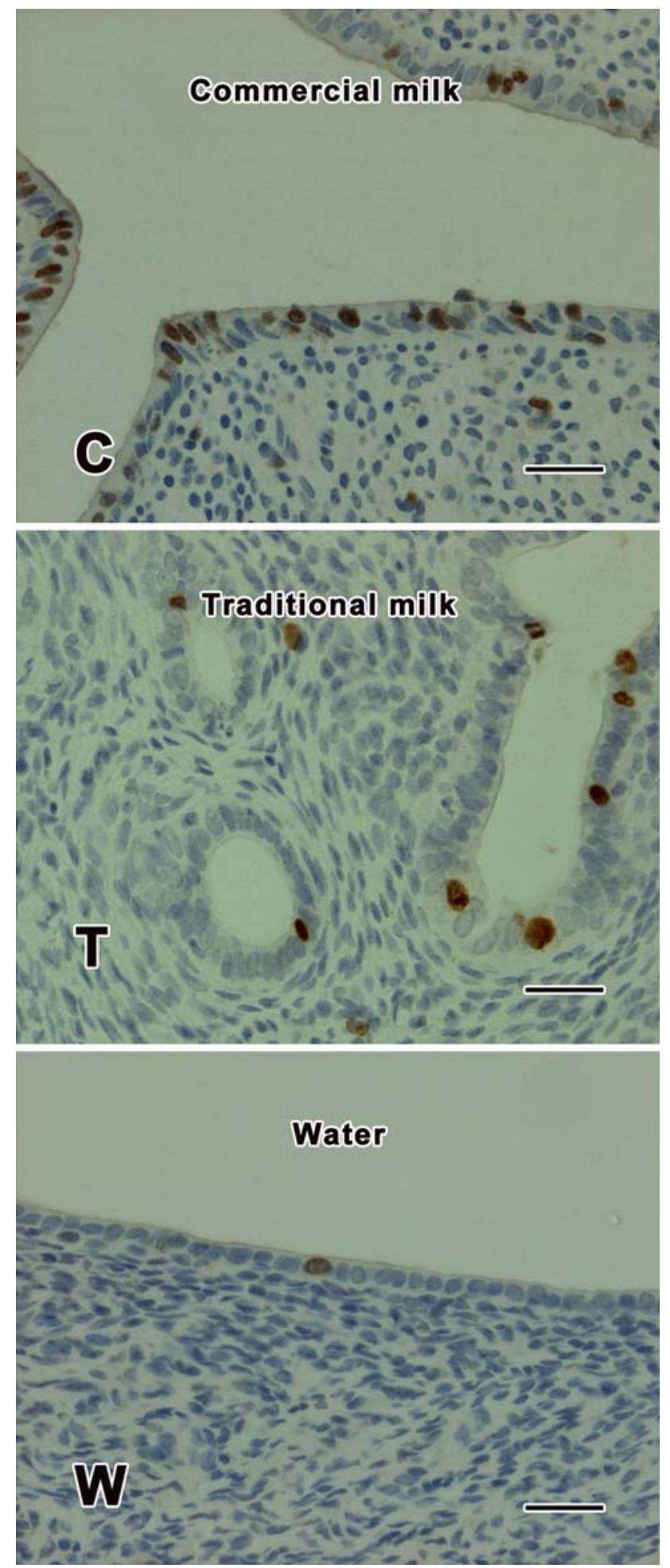

Fig. 1 Light micrographs of immunostained BrdU-labeled cells in the epithelia among the three experimental groups. Positively labeled endothelia have a darkly stained nucleus and peri-nuclear immunostaining that indicates S-phase cells. The $\mathrm{C}$ group had the highest frequency of BrdU-labeled cells, followed by the $\mathrm{T}$ and then the $\mathrm{W}$ groups. The irregular morphology of epithelia was observed in the $\mathrm{C}$ and T groups. Bars: $50 \mu \mathrm{m}$
Table 5 The labeling index of the uterine epithelium and endothelium gland epithelium

\begin{tabular}{lll}
\hline Groups & Epithelium & Endometrium gland epithelium \\
\hline Commercial milk & $8.9 \pm 1.1$ & $7.9 \pm 0.9$ \\
Traditional milk & $3.3 \pm 0.4 \mathrm{a}$ & $3.9 \pm 0.5 \mathrm{a}$ \\
Water & $0.7 \pm 0.1 \mathrm{a}, \mathrm{b}$ & $0.9 \pm 0.1 \mathrm{a}, \mathrm{b}$ \\
\hline
\end{tabular}

ANOVA analysis for comparison among groups. Values (\%) are given as the mean $\pm \mathrm{SD}$

Values followed by different letters indicate signficant differences. $a$ Significant difference from the commercial milk group $(n=15$; $p<0.05) ; b$ significant difference from the traditional milk group $(n=15 ; p<0.001)$

markedly increase. Thus, in terms of estrogen and progesterone levels traditional milk should be significantly different from modern commercial milk [17]. This hypothesis is supported by our results that indeed did show that the concentrations of estrogens and progesterone were much higher in the commercial milk than in the traditional milk. This is one explanation of why the $\mathrm{T}$ group, as a natural control, was markedly different from the $\mathrm{C}$ group in terms of uterotrophic effects. After 1 week of exposure to different liquids, the uterine weight and ratio of uterine weight to body weight of the sacrificed rats were in the order of $\mathrm{C}$ group $>\mathrm{T}$ group $>\mathrm{W}$ group. Morphologic parameters of estrogenicity, including uterine epithelial cell height, endometrium height, uterine labeling index of epithelium and endometrium gland epithelium, also showed similar patterns, suggesting that the different uterotrophic effects among the three groups were due to the different concentrations of estrogens and progesterone to which they were exposed. Researchers have found that hormones in milk can cause an increased frequency of mammary and prostate tumors in rats [16, 23, 24]. Moreover, some human studies have demonstrated that milk consumption increases the level of estrogen in circulation. South African black males that switched from a vegetarian to a Western diet with milk and butter showed an increase in circulating estrogen levels [25]. The existence of a relationship between milk consumption and plasma estrogen concentration is supported by the fact that Asian women, who consume little milk and few dairy products, have a lower plasma estrogen concentration than Caucasian women, whose dairy product consumption is relatively high [26]. In our study, the plasma levels of estrogen and progesterone were higher in the $\mathrm{C}$ and $\mathrm{T}$ groups than in the $\mathrm{W}$ group. This explains, at least in part, the differences in uterotrophic effects among the $\mathrm{C}, \mathrm{T}$, and $\mathrm{W}$ groups.

The relationship between estrogen and uterotrophic effects is well established. The role of estrogen in uterotrophic effects is regulated by the estrogen receptor [27]. 
In sexually immature rodents, estrogen stimulates DNA synthesis and cell proliferation in all uterine compartments [28]. In adult female estrogen receptor knockout mice, there is a loss of estrogen responsiveness, including a hypoplastic uterus; the same is exhibited in mice with disruption of the estrogen-responsive ring finger protein gene $[29,30]$. Therefore, it seems reasonable that the highest uterine weight and most marked morphological parameters of the uterotrophic effects were exhibited in the $\mathrm{C}$ group, which were exposed to the highest estrogen level via commercial milk.

The relationship between progesterone and uterotrophic effects remains to be identified. Most actions of progesterone are mediated via the progesterone receptor (PR) [31]. This receptor is one of the most intensely studied estrogen-regulated genes and is widely recognized as a marker of estrogen activity [32]. Clusters of estrogen response element (ERE) half-sites, which are essential for transactivation of the PR gene by liganded response elements, are present within the PR gene promoter [33-35]. Almost all hormone treatment protocols designed to elicit effects of progesterone involve preparatory estrogen priming to induce PR $[36,37]$. Therefore, it is possible that the combination of estrogen and progesterone in milk had uterotrophic effects on the immature ovariectomized rats.

If other EDCs were present in the milk, they do not appear to have played an important role in the significant differences in uterotrophic effects between $\mathrm{C}$ and $\mathrm{T}$ groups. Estrogens in milk have the same structure as endogenous estrogens, which have been found to possess an estrogenic potency 100 to 100,000 -fold greater than that of EDCs [38]. Thus, the effects of other EDCs are concealed by the strong effects of estrogens in milk. Moreover, the commercial and traditional types of milk used in this study came from cows bred in the same grassland and exposed to the same environment; consequently, they had the same chance of exposure to other EDCs. Thus, we speculate that these other EDCs, whatever their concentration, would not affect the difference between the uterotrophic effects in the $\mathrm{C}$ and $\mathrm{T}$ groups.

In conclusion, our findings demonstrate that estrogens in milk have significant uterotrophic effects on immature ovariectomized rats. The adverse effects of estrogens in milk should be considered to be very important.

Acknowledgments Our study was supported by a grant from National Natural Science Foundation of China (No. 30671759).

\section{References}

1. Crews D, McLachlan JA. Epigenetics, evolution, endocrine disruption, health, and disease. Endocrinology. 2006;147:S4-10.
2. Rodriguez EM, Medesani DA, Fingerman M. Endocrine disruption in crustaceans due to pollutants: a review. Comp Biochem Physiol A Mol Integr Physiol. 2007;146:661-71.

3. Buck Louis GM, Lynch CD, Cooney MA. Environmental influences on female fecundity and fertility. Semin Reprod Med. 2006;24:147-55.

4. Whitehead SA, Rice S. Endocrine-disrupting chemicals as modulators of sex steroid synthesis. Best Pract Res Clin Endocrinol Metab. 2006;20:45-61.

5. Fenton SE. Endocrine-disrupting compounds and mammary gland development: early exposure and later life consequences. Endocrinology. 2006;147:S18-24.

6. Cunningham AR, Cunningham SL, Rosenkranz HS. Structureactivity approach to the identification of environmental estrogens: the MCASE approach. SAR QSAR Environ Res. 2004;15:55-67.

7. Nakari T. Estrogenicity of municipal effluents assessed in vivo and in vitro. Environ Toxicol. 2004;19:207-15.

8. Martin OV, Lai KM, Scrimshaw MD, Lester JN. Receiver operating characteristic analysis for environmental diagnosis. A potential application to endocrine disrupter screening: in vitro estrogenicity bioassays. Environ Sci Technol. 2005;39:5349-55.

9. U.S. Environmental Protection Agency. Endocrine Disrupter Screening and Testing Advisory Committee (EDSTAC) final report. Washington, DC; 1998. p. 95.

10. Armendariz C, Perez de Ciriza JA, Farre R. Gas chromatographic determination of organochlorine pesticides in cow milk. Int J Food Sci Nutr. 2004;55:215-21.

11. Armstrong B, Doll R. Environmental factors and cancer incidence and mortality in different countries, with special reference to dietary practices. Int J Cancer. 1975;15:617-31.

12. Ganmaa D, Li XM, Wang J, Qin LQ, Wang PY, Sato A. Incidence and mortality of testicular and prostatic cancers in relation to world dietary practices. Int J Cancer. 2002;98:262-7.

13. Cho E, Spiegelman D, Hunter DJ, Chen WY, Stampfer MJ, Colditz GA, et al. Premenopausal fat intake and risk of breast cancer. J Natl Cancer Inst. 2003;95:1079-85.

14. Knekt P, Jarvinen R, Seppanen R, Pukkala E, Aromaa A. Intake of dairy products and the risk of breast cancer. $\mathrm{Br} \mathrm{J}$ Cancer. 1996;73:687-91.

15. Michels KB, Rosner BA, Chumlea WC, Colditz GA, Willett WC. Preschool diet and adult risk of breast cancer. Int $\mathrm{J}$ Cancer. 2006;118:749-54.

16. Zhou H, Qin LQ, Tang FL, Ma DF, Wang PY, Wang Y. Effect of milk on the 7, 12-dimethylbenz[a]-anthracene-induced mammary tumor model in rat. Food Chem Toxicol. 2007;45:1868-72.

17. Ganmaa D, Wang PY, Qin LQ, Hoshi K, Sato A. Is milk responsible for male reproductive disorders? Med Hypotheses. 2001;57:510-4.

18. Yamasaki K, Takeyoshi M, Sawaki M, Imatanaka N, Shinoda K, Takatsuki M. Immature rat uterotrophic assay of 18 chemicals and Hershberger assay of 30 chemicals. Toxicology. 2003; 183:93-115.

19. Padilla-Banks E, Jefferson WN, Newbold RR. The immature mouse is a suitable model for detection of estrogenicity in the uterotrophic bioassay. Environ Health Perspect. 2001;109:821-6.

20. Sawaoka H, Kawano S, Tsuji S, Tsujii M, Gunawan ES, Takei Y, et al. Cyclooxygenase-2 inhibitors suppress the growth of gastric cancer xenografts via induction of apoptosis in nude mice. Am J Physiol. 1998;274:G1061-7.

21. Ganmaa D, Tezuka H, Enkhmaa D, Hoshi K, Sato A. Commercial cows' milk has uterotrophic activity on the uteri of young ovariectomized rats and immature rats. Int J Cancer. 2006; 118:2363-5.

22. Severin S, Wenshui X. Milk biologically active components as nutraceuticals: review. Crit Rev Food Sci Nutr. 2005;45:645-56. 
23. Qin LQ, Xu JY, Wang PY, Ganmaa D, Li J, Wang J, et al. Low-fat milk promotes the development of 7, 12-dimethylbenz(a)anthracene (DMBA)-induced mammary tumors in rats. Int J Cancer. 2004;110:491-6.

24. Qin LQ, Xu JY, Wang PY, Kaneko T, Hoshi K, Sato A. Milk consumption is a risk factor for prostate cancer: meta-analysis of case-control studies. Nutr Cancer. 2004;48:22-7.

25. Hill P, Wynder EL, Garnes H, Walker ARP. Environmental factors, hormone status, and prostatic cancer. Prev Med. 1980; 9:657-66.

26. Bernstein L, Ross RK. Endogenous hormones and breast cancer risk. Epidemiol Rev. 1993;15:48-65.

27. O'Brien JE, Peterson TJ, Tong MH, Lee EJ, Pfaff LE, Hewitt SC, et al. Estrogen-induced proliferation of uterine epithelial cells is independent of estrogen receptor alpha binding to classical estrogen response elements. J Biol Chem. 2006;281:26683-92.

28. Inada K, Hayashi S, Iguchi T, Sato T. Establishment of a primary culture model of mouse uterine and vaginal stroma for studying in vitro estrogen effects. Exp Biol Med. 2006;231:303-10.

29. Lubahn DB, Moyer J, Golding T, Couse J, Korach K, Smithies O. Alteration of reproductive function but not prenatal sexual development after insertional disruption of the mouse estrogen receptor gene. Proc Natl Acad Sci USA. 1993;90:11162-6.

30. Orimo A, Inoue S, Minowa O, Tominaga N, Tomioka Y, Sato M, et al. Underdeveloped uterus and reduced estrogen responsiveness in mice with disruption of the estrogen-responsive finger protein gene, which is a direct target of estrogen receptor alpha. Proc Natl Acad Sci USA. 1999;96:12027-32.
31. Lydon JP, DeMayo FJ, Funk CR, Mani SK, Hughes AR, Montgomery CA Jr, et al. Mice lacking progesterone receptor exhibit pleiotropic reproductive abnormalities. Genes Dev. 1995;9:226678.

32. Graham JD, Clarke CL. Physiological action of progesterone in target tissues. Endocr Rev. 1997;18:502-19.

33. Kastner P, Krust A, Turcotte B, Stropp U, Tora L, Gronemeyer H, et al. Two distinct estrogen-regulated promoters generate transcripts encoding the two functionally different human progesterone receptor forms A and B. EMBO J. 1990;9:1603-14.

34. Kraus WL, Montano MM, Katzenellenbogen BS. Identification of multiple, widely spaced estrogen-responsive regions in the rat progesterone receptor gene. Mol Endocrinol. 1994;8:952-69.

35. Petz LN, Nardulli AM. Sp1 binding sites and an estrogen response element half-site are involved in regulation of the human progesterone receptor A promoter. Mol Endocrinol. 2000; 14:972-85.

36. Hofseth LJ, Raafat AM, Osuch JR, Pathak DR, Slomski CA, Haslam SZ. Hormone replacement therapy with estrogen or estrogen plus medroxyprogesterone acetate is associated with increased epithelial proliferation in the normal postmenopausal breast. J Clin Endocrinol Metab. 1999;84:4559-65.

37. Turgeon JL, McDonnell DP, Martin KA, Wise PM. Hormone therapy: physiological complexity belies therapeutic simplicity. Science. 2004;304:1269-73.

38. Safe SH. Environmental and dietary estrogens and human health: is there a problem? Environ Health Perspect. 1995;103:346-51. 